\title{
Analysis of Diagrid Structural System by E-Tab
}

\author{
U. A. Nawale ${ }^{1}$, D. N. Kakade ${ }^{2}$ \\ Research Scholar, Civil Engg Department, Dr. Babasaheb Ambedkar Marathwada University, Aurangabad, India ${ }^{1}$ \\ Professor, Civil Engg Department, Dr. Babasaheb Ambedkar Marathwada University, Aurangabad, India²
}

\begin{abstract}
Now days high rise structures are rapidly grow due to limitation of available land. Structure design of high rise buildings is governed by the lateral loads due to wind or earthquake. Lateral load resistance of structure is provided by wall frame, braced tube, shear wall, outrigger and tubular system. Recently the digrid-diagonal grid system is widely used for tall buildings due to its structural efficiency. In this paper, study of 32-storey digrid structural system without vertical column around periphery building is presented here. The comparison of analysis of result in terms of storey displacement, storey drifts for they are presented here.
\end{abstract}

Keywords: Diagrid Building, Storey Drift, Storey Displacement, E-Tab.

\section{INTRODUCTION}

Generally, the function of tall buildings has been as commercial office buildings. Other usages, such as residential, mixed-use, and hotel tower developments have since rapidly increased. Tall building development involves various complex factors such as economics, aesthetics look, technology, municipal regulations, and politics. Among these, economics has been the primary governing factor. For a very tall building, its structural design is generally governed by its lateral stiffness. The Digrid are diagonal members which are involved both in gravity and in lateral load resisting system. The Digrid systems are the evolution of braced tube structures, since the perimeter configuration still holds for preserving the maximum bending resistance and rigidity, while, with respect to the braced tube, the mega-diagonal members are diffusely spread over the façade, giving rise to closely spaced diagonal elements and allowing for the complete elimination of the conventional vertical columns. Therefore the diagonal members in digrid structures act both as inclined columns and as bracing elements, and carry gravity loads as well as lateral forces; due to their triangulated configuration, mainly internal axial forces arise in the members, thus minimizing shear racking effects. Digrid system around perimeter saves approximately 20 precent of the structural steel weight when compared to a conventional moment-frame structure.

In this paper, a study of 30 storeys Digrid Building without straight column around periphery is considered with building height $95 \mathrm{~m}$. Comparison of analysis result in terms of storey Drift and point displacement are presented here.

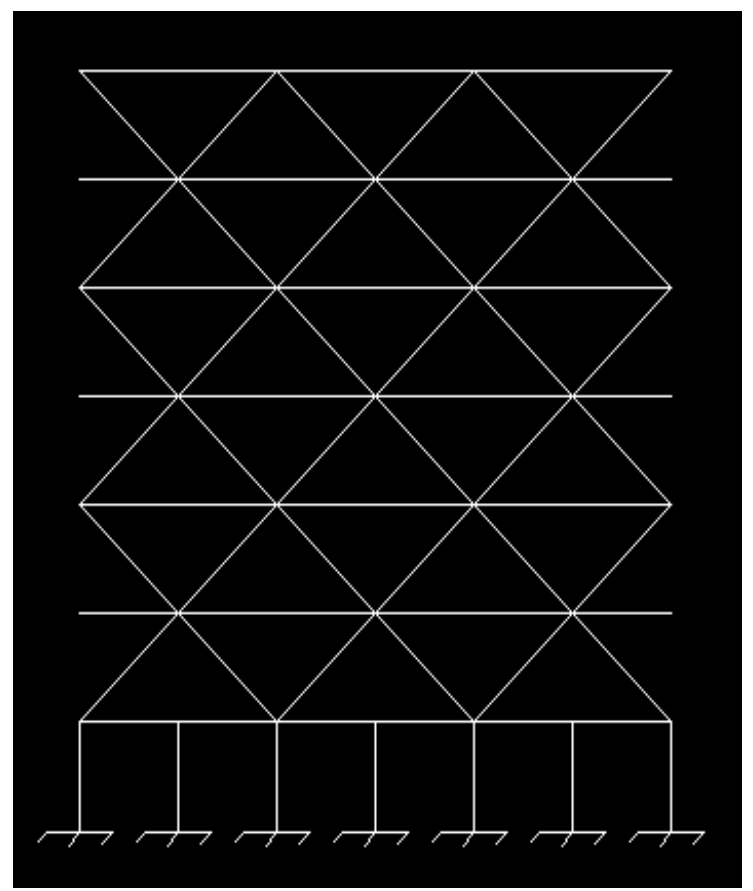

Fig. 1 Typical Elevation of Digrid Structure 
UGC Approved Journal

IARJSET

Vol. 4, Issue 6, June 2017

\section{ANALYSIS OF 32-STOREY BUILDING}

\section{Building Configuration}

The 32- storey building is having unsymmetrical dimension and $95 \mathrm{~m}$ total height of building. The storey height is $3 \mathrm{~m}$. The plan and elevation are shown in figure (2) and figure (3). without vertical column around periphery. The column sizes are 300X600, 230X600 and Beam size is 230X450. The diagonal member's (Digrid) size is $23 \mathrm{mmx} 230 \mathrm{~mm}$

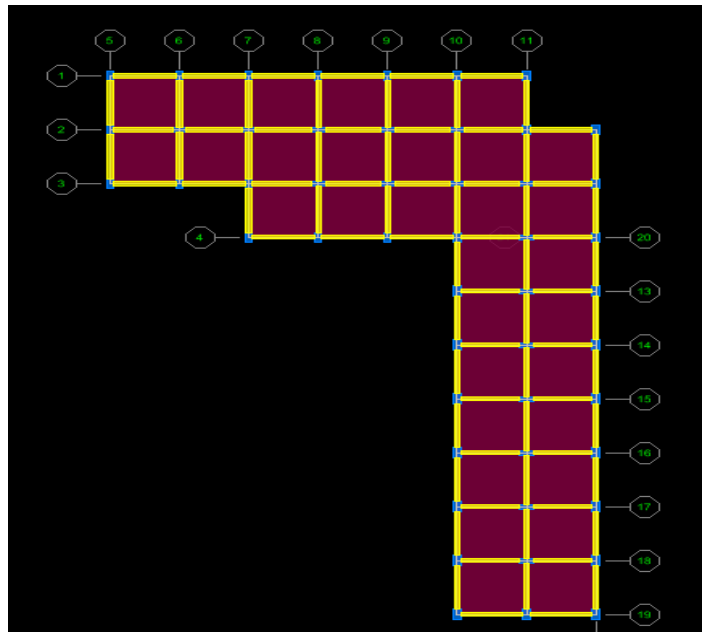

Fig. 2 Plan

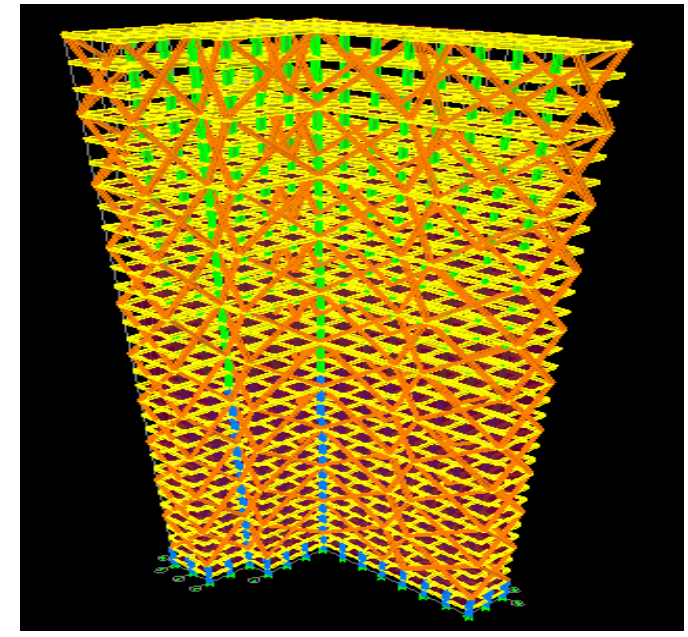

Fig. 3 3D View of Building

The live load and dead load are $3 \mathrm{kN} / \mathrm{m}$ and $1 \mathrm{kN} / \mathrm{m}^{2}$ respectively. The design earthquake load is computed based on the zone factor 0.16, soil type III, Importance factor 1, Response reduction 5 as per IS-1893-2002. The design wind load is computed based on location Pune, wind speed 39m/s, Terrain category 3, Structure class B, Risk coefficient 1.06 , Topography factor 1 . Modelling analysis and design of models are carried out using ETAB. The end condition for models are assumed as hinged. The support conditions are as fixed. Modal combination CQC and Directional Combination SRSS is used for Response Spectrum Analysis.

\section{Methodology of Preliminary Design of Diagrid Structures}

In this section, a simple methodology for the preliminary design of diagrid structures is introduced. As was discussed earlier, typical braced cores contribute only 15-20\% of the total lateral rigidity in properly designed diagrid tall buildings. For this reason and because we can more accurately estimate the lateral rigidity provided by diagrids, all the required lateral stiffness is allocated to the diagrids.

The procedure begins by specifying the contributions to the total lateral displacement of the structure due to bending and shear deformation. This allocation is based on an assessment of the intrinsic attributes of diagrid structures and the behavioral characteristics of tall buildings related to their height to width ratio, and leads to the required values of shear and bending deformation. Simple equations which convert these required deformation values into cross-sectional areas for the diagrid members are derived.

This design methodology is applied to several diagrid structures of various heights and aspect ratios. Based on these studies, empirical guidelines for assessing the relative contribution of bending and shear deformation to the total lateral displacement of diagrid tall structures are derived. With this formula, the preliminary member sizing process is essentially automated.

\section{Shear stiffness and bending stiffness of diagrids structure}

We model the building as a beam, and subdivide the beam longitudinally into modules according to the repetitive diagrid pattern. Each module is defined by a single level of diagrids that extend over n stories. Figure illustrates the case of a 32-story module. Depending upon the direction of loading, the faces act as either web or flange elements. The diagonal members are assumed to be pin-ended, and therefore to resist the transverse shear and moment through only axial action. With this idealization, the design problem reduces to determining the cross-sectional area of typical web and flange members for each module. We establish these quantities with a stiffness-based approach

\section{ANALYSIS RESULTS}

The analysis result in terms of storey drift and displacement of point object no. 25 are presented here for Static, Dynamic and Wind Analysis. 
UGC Approved Journal

IARJSET

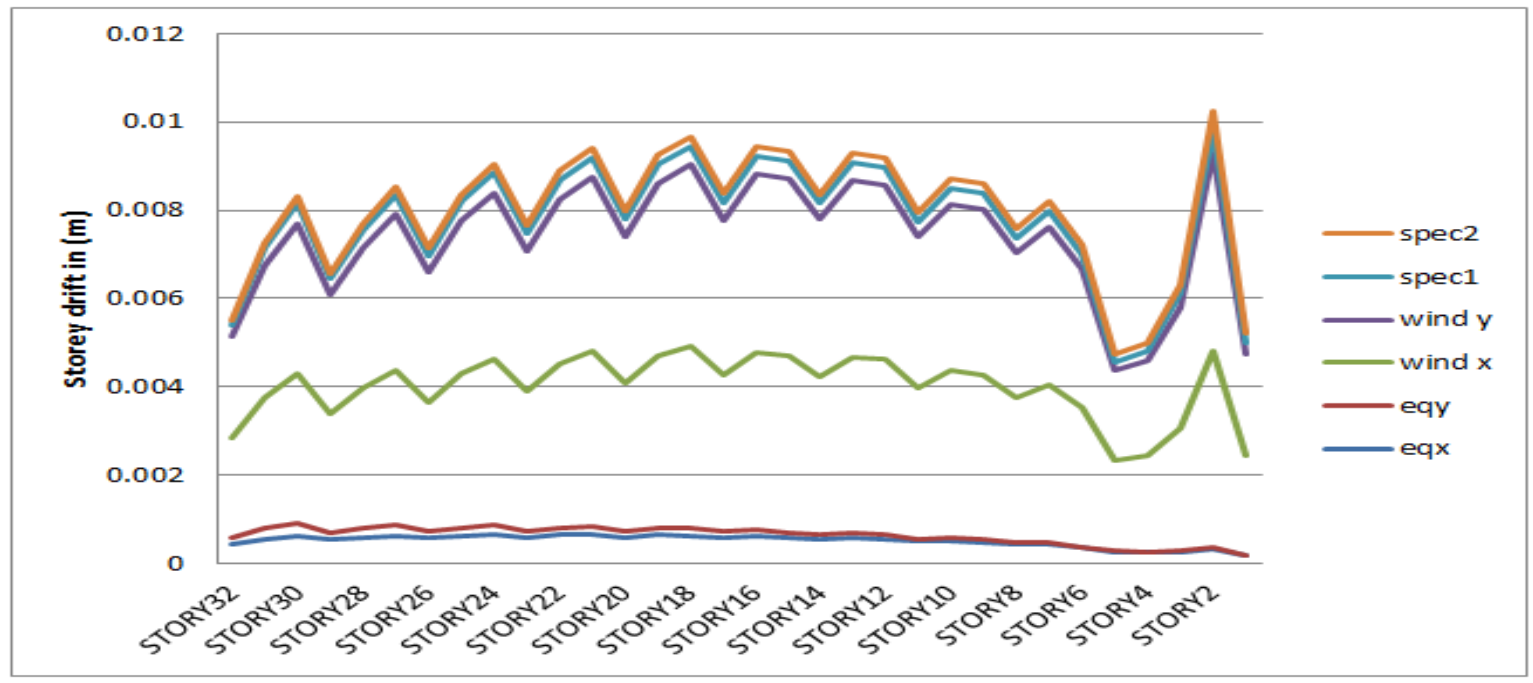

Fig. 4 Storey vs. Storey Drift $-\mathrm{X}$ Direction

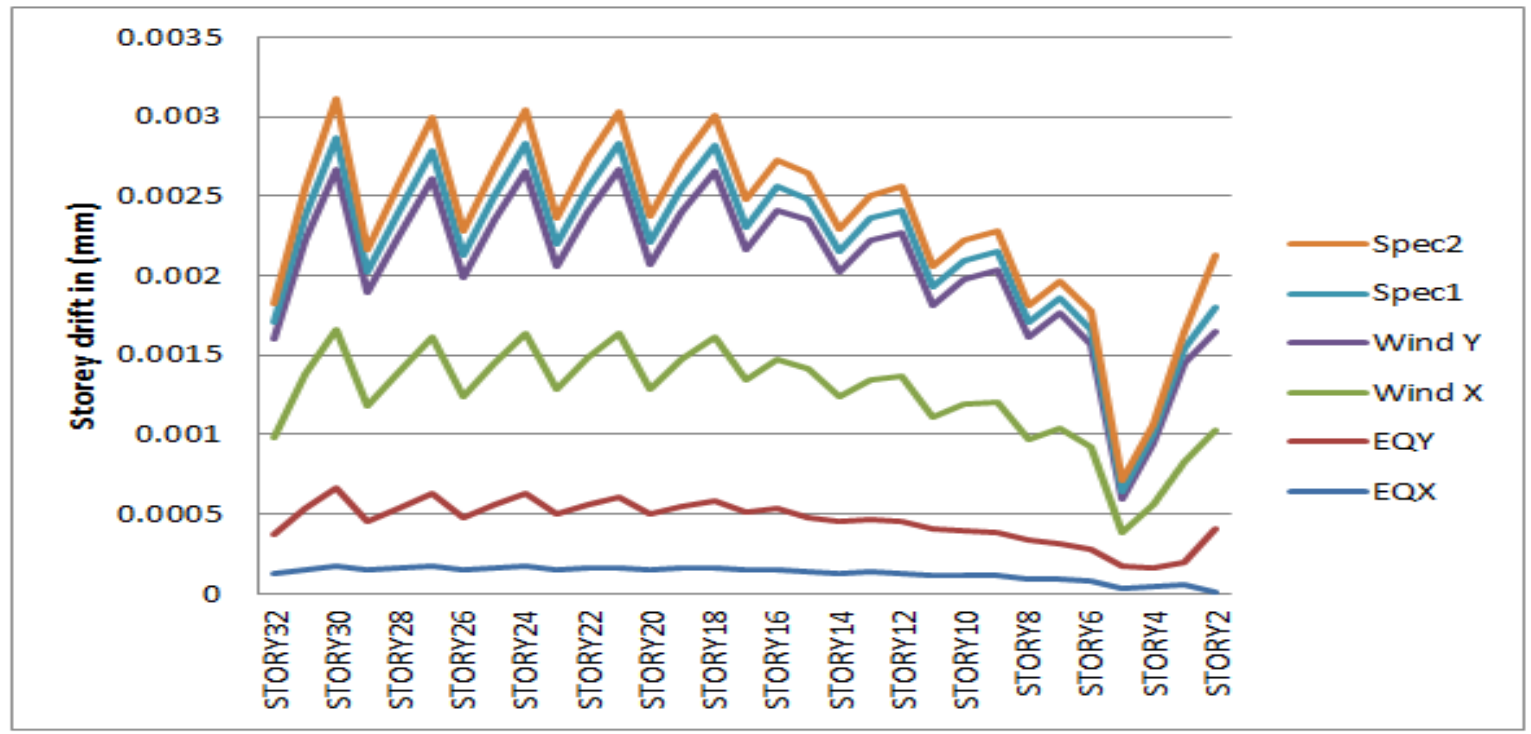

Fig.5 Storey vs. Storey Drift -Y Direction

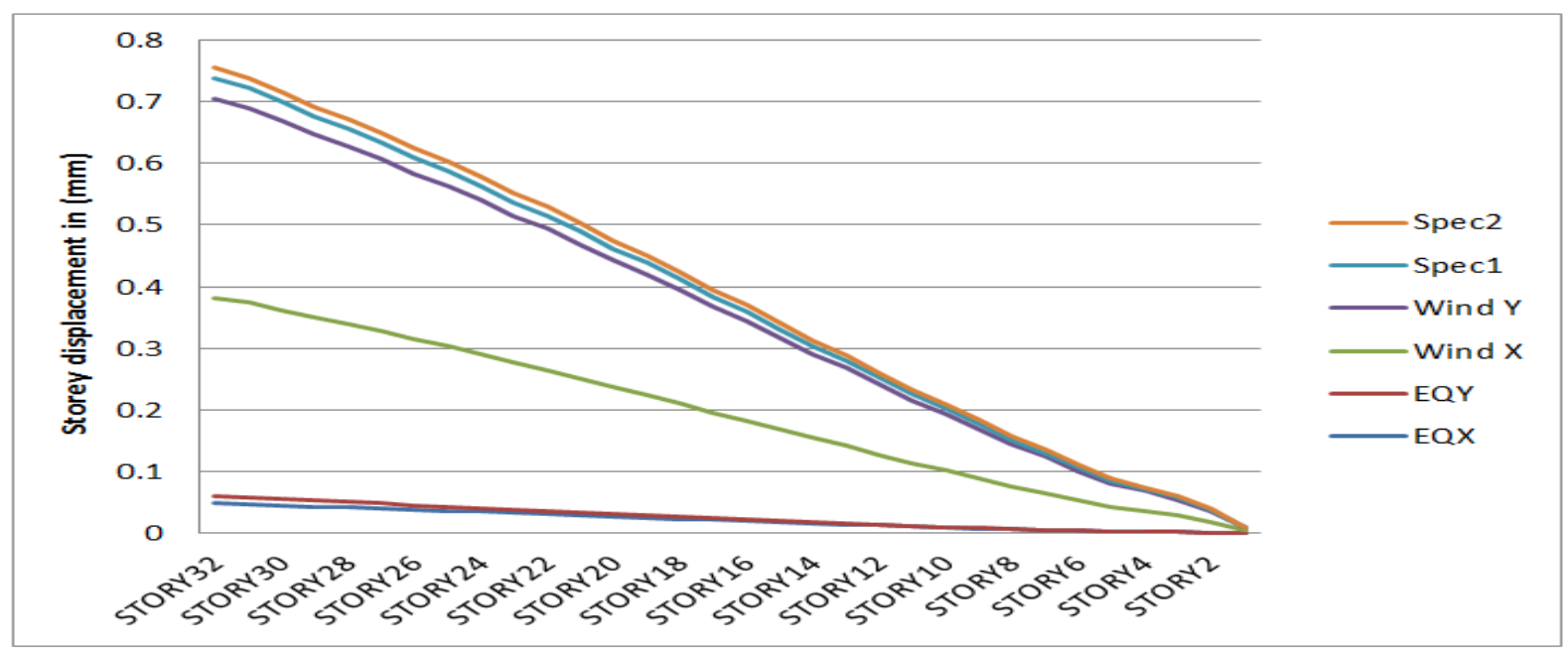

Fig. 6 Storey vs. Storey Displacement -X Direction 
UGC Approved Journal

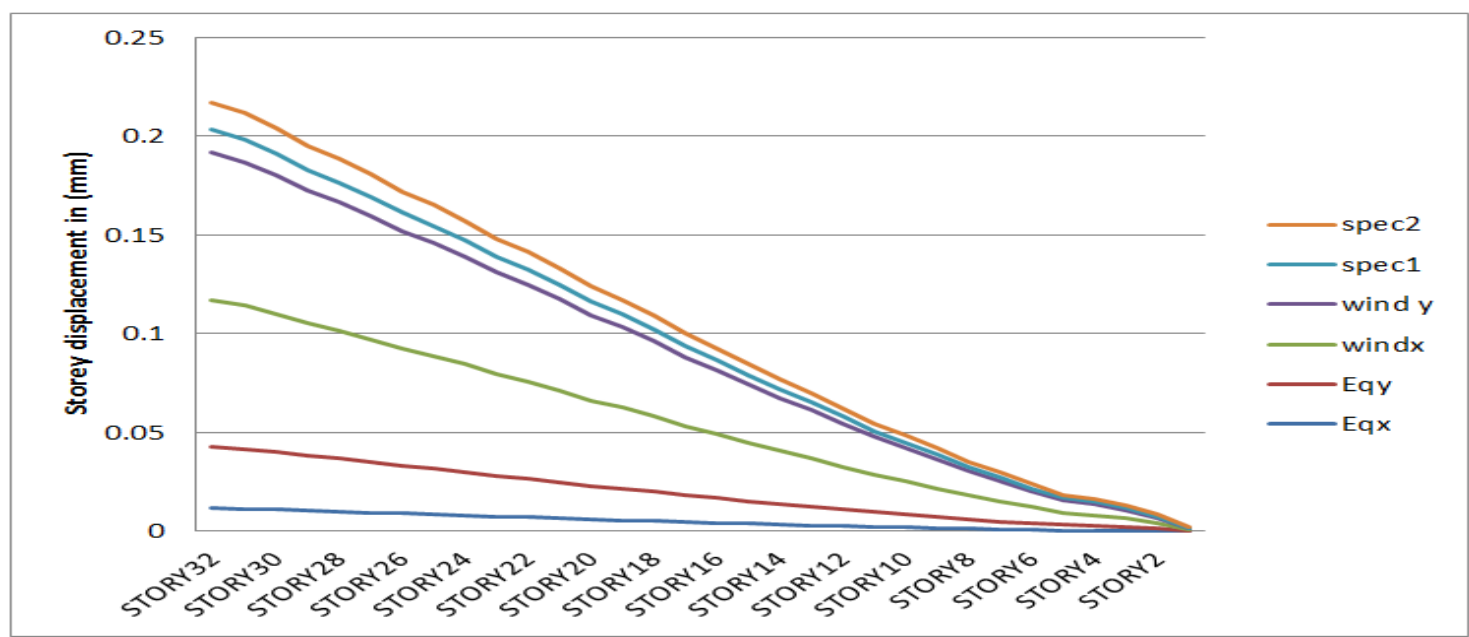

Fig. 4 Storey vs. Storey Displacement -Y Direction

\section{CONCLUSION}

1. It is observed that Lateral Displacement is higher for the case of dynamic analysis than static analysis. It is observed that wind analysis is lower resulting than Dynamic Response Spectrum analysis but higher than static analysis.

2. Structural performance: Diagrid building shows less lateral displacement and drift in comparison to conventional building.

3. Material saving property: Although volume of concrete used in both building is approx. same, but diagrid shows more economical in terms of steel used. Diagrid building saves about $33 \%$ steel without affecting the structural efficiency.

4. Better resistance to lateral loads: Due to diagonal columns on its periphery, Diagrid shows better resistance to lateral loads and due to this, inner columns get relaxed and carry only gravity loads. While in conventional building both inner and outer column are designed for both gravity and lateral loads.

5. Aesthetic look: In comparison to conventional building, Diagrid buildings are more aesthetic in look and it becomes important for high rise buildings.

\section{REFERENCES}

[1] Hoang ChiTran a, HyoSeonPark b, JaehongLee a,n "A unique feasible mode of prestress design for cable domes" a Department of Architectural Engineering, Sejong University, 98Kunja Dong,KwangjinKu,Seoul 143-747,Republicof Korea.

[2] P. Irwin, J. Kilpatrick, J. Robinson and A. Frisque, "Wind and Tall Buildings: Negatives and Positives",The Structural Design of Tall and Special Buildings, Vol. 17, (2008), pp. 915-928.

[3] Khushbu jani and paresh V. Patel, "Analysis and Design of digrid Structural System for High rise Steel Building Published by Elsevier Ltd.

[4] Kyoung S Moon, "Digrid Structure for Complex shaped Tall Building “, published By Elsevier Ltd.

[5] Charnish B. and McDonnell T. "The Bow: Unique digrid Structural System for sustainable Tall Building" CTBUH 8th World congres s, Dubai.

[6] Kareen T. Kijewski etal, "Mitigation of Motion of Tall Building With Specific Example of recent application "Wind and Structures Vol. 2 No. 3 1999, pp. 201-251 